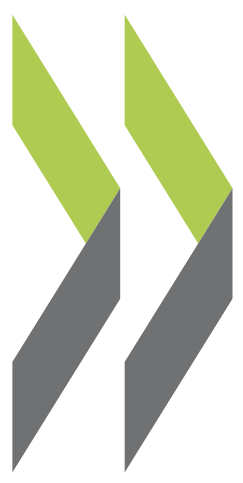

PEB Exchange, Programme on Educational Building 2008/08

A Flexible School for Early Childhood Education in Italy

\author{
Giorgio Ponti
}

https://dx.doi.org/10.1787/241342175021 


\section{A Flexible School for Early Childhood Education in Italy}

By Giorgio Ponti, CISEM, Italy

(based on information provided by Massimilano Mandarini)

The design of this flexible school for early childhood education in Milan, Italy, takes into account children's development and the different ways they experience space according to their age. The facilities will include not only a nursery school and kindergarten, but also a drop-in day-care centre, a play centre and outdoor areas to develop the senses.
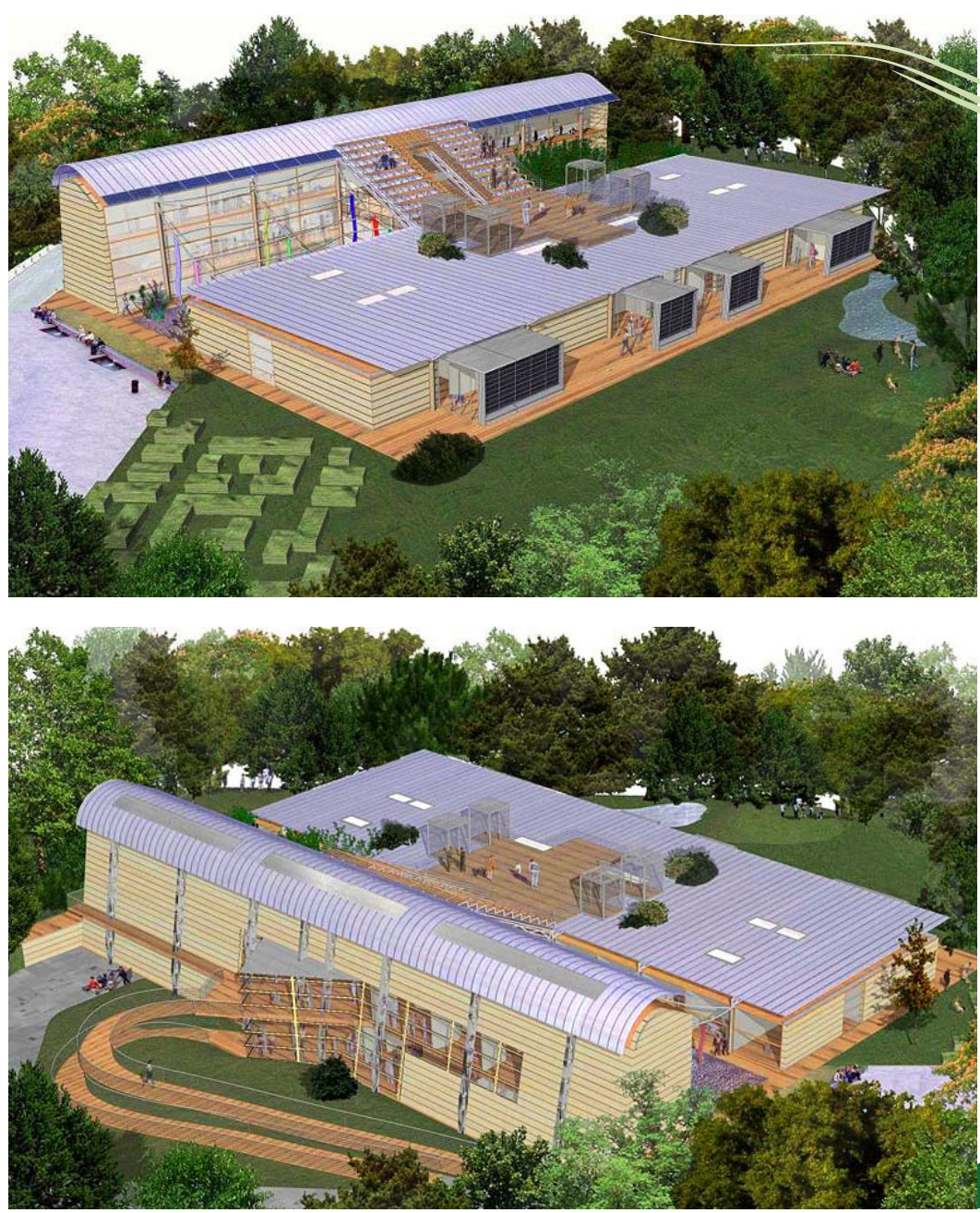

This school building will respond to the need for a facility that can later be expanded to become the key educational site for the neighbourhood, a place for gathering and interacting outside of school hours, not only for children but also for adults. Attention focuses on developing a unified and coherent educational project that targets newborns to six-year-olds, and architecture that can be expanded to the elementary and secondary levels through a system of "flexible and growing buildings" while meeting the various needs of different age groups.

This choice of architecture aims to allow flexible learning. Space becomes a resource that supports educational objectives and fosters the safety and emotional well-being of children and staff. Because children's needs, motivations, and cognitive, motor and social skills change as they grow, early-childhood education should be based on the concept of the active, curious and imaginative child, who learns by 
interacting with the physical and social environment. The purpose is to enable children to build their personal identity, leave their mark, relate to others, and develop their creativity, imagination and ability to think. In this project, the spaces devoted to play can be extended to many areas that have a specific educational and emotional value, promoting all forms of participation and interaction between children, between children and adults, and between the school and families. Several groups can engage in different activities at the same time.

Another objective is to use architecture to introduce the aesthetic dimension into education. The building can enhance the appreciation of beauty, colour and form and provide a setting in which children experience an environment that is familiar, but also that can be changed in unexpected ways. The facilities can thus encourage discovery, curiosity, participation and a desire to be attentive and communicate. This approach aims to promote a "narrative" learning process that "speaks" to children, tells a story, shows how things are done and leaves an imprint on their mind. The school building can also serve to focus on themes that have a special educational value for the community, such as respect for the environment, the use of local materials, energy efficiency, the rational consumption of both traditional and renewable energy sources, and criteria for eco-compatible and sustainable buildings.

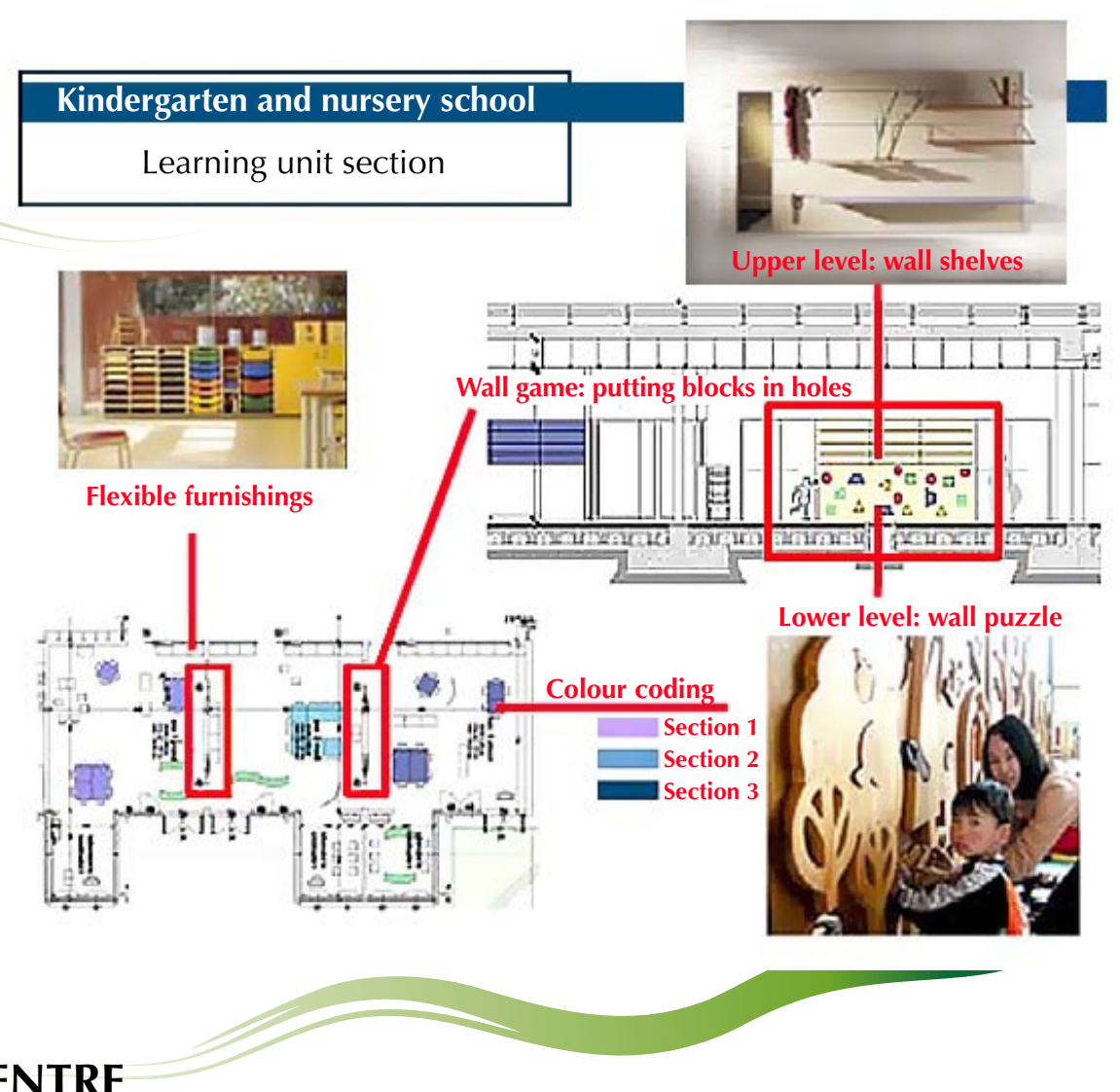

\section{DROP-IN DAY-CARE CENTRE}

The drop-in day-care centre will be located in the school's semi-basement area, 2.15 metres below ground level. The space will be divided into three areas:

- Entrance and corridor: A long corridor will extend from the entrance to the play area. Along the corridor will be coatracks of different heights and colours, a storage area for strollers and a series of coloured shelves for books and other supplies for the day-care centre. 
- Play area: This will be an open area with two types of flooring, one half wooden and the other a soft surface providing protection against falls. The furnishings will consist of soft walls, cusions, toy baskets, shelves for books and crayons, a small table, and a small puppet theatre with chairs.

- Rest area: The rest area will have soft flooring and be painted a relaxing shade of blue. This area will contain beds of various sizes for napping.

\section{Play centre}

The play centre will extend in a straight line along the entire top floor of the school complex. Its entrance will be centrally located and divide the play centre into two wings. On one side of the entrance will be the image and movement area and on the other the creative area. These areas will in turn be divided into the following thematic spaces (described below):

- entrance area: climbing wall and coatroom;

- image and movement area: planetarium, Cube Cinema, Cartoonland and Raid Adventure;

- creative area: Hidden Forest, etc.

\section{Planetarium}

The planetarium will be a simple room with a semi-spherical dome made of plasterboard representing the sky. The dome will have holes of varying sizes through which light passes, to show the main constellations of the Northern Hemisphere. This dome will be painted dark blue and covered with fluorescent lines to illustrate the constellations, along with educational notes. The floor will be raised 70 centimetres above normal floor level, with a corrugated surface covered with soft, fall-protection material. Small matresses and soft objects will be the only pieces of furniture.

\section{Cube Cinema}

In front of the planetarium will be the Cube Cinema, a cubic module, made of prefabricated wood, in which small groups of children can watch films, cartoons, educational slides, etc. The exterior of the Cube Cinema will be painted to resemble the famous Rubik's cube with a checkerboard pattern in basic colours (yellow, red, blue, white).

\section{Cartoonland}

Cartoonland will be a sloping wall where children can make murals and collages of their own creation or featuring their favorite cartoon characters. It will be a dynamic space that will change over time according to the children's preferences. Drawings, objects and cut-outs of all sorts can be put on the wall.

\section{Raid Adventure}

Raid Adventure will be the space devoted to movement. A castle-like structure made of wood and bamboo, it will have three levels:

- A lower level - the "sea cave" - will suggest the underwater world, with cave-like plasterboard walls and blue lighting.

- A middle level, made of elastic material filled with small plastic balls, will be a moving area in which children can dive, jump and play. 
- The third level will consist of a Tibetan rope bridge for the most co-ordinated and agile children and ropes for climbing down to the ground.

The floor around the castle will be covered with fall-protection material.

Children will access the movement area by crawling through the Geode, a large, hollow globe representing Earth; the tunnel leading to the castle will be covered with fluorescent educational notes about our planet.

\section{Hidden Forest}

The creative area will open with a space where giant, cloth baskets in the shape of mushrooms, trees and fruit hang will suspend from the ceiling. The children can climb into the baskets and swing gently in the dim light inside them.

A square table that can be raised or lowered (for smaller children) will have boxes of crayons and paper. The seats will be stuffed cubes of various colours and sizes covered with washable, waterproof cloth.

From the middle of the room to the sloped wall, the flooring will be in soft material. This same material will cover the wall to a height of 1 metre, and cushions for children to lean on can be attached to it with velcro. The children can take the detachable cushions wherever they wish or simply change their position on the wall.

\section{Outdoor areas}

The park, landscaping, outdoor facilities and play areas are designed and organised around the theme of the five senses, the four elements and the three dimensions. The project is being developed with a view to teach children about the agricultural landscape of the Po Valley, so that they can learn directly from nature about life cycles, the four seasons and the ecosystem.

The relationship between various aspects of the ecosystem are presented in areas for each of the senses that can be understood by children of different ages; the five senses park will include the following areas:

- taste: vegetable gardens, greenhouses and a learning orchard;

- hearing: water and stone courts, fountains and water-related games, the "Valley of Sounds", a canal and organic pool maintained through phytodepuration;

- smell: the "Labyrinth of Smells" and systems for experiencing aromas;

- touch: various natural ground surfaces for their softness, hardness, warmth and coolness;

- sight: the surrounding hills, a treehouse, a play area for games, a deck, a changing landscape with new plantings and enclosures with the various trees typical of the traditional Lombardy landscape.
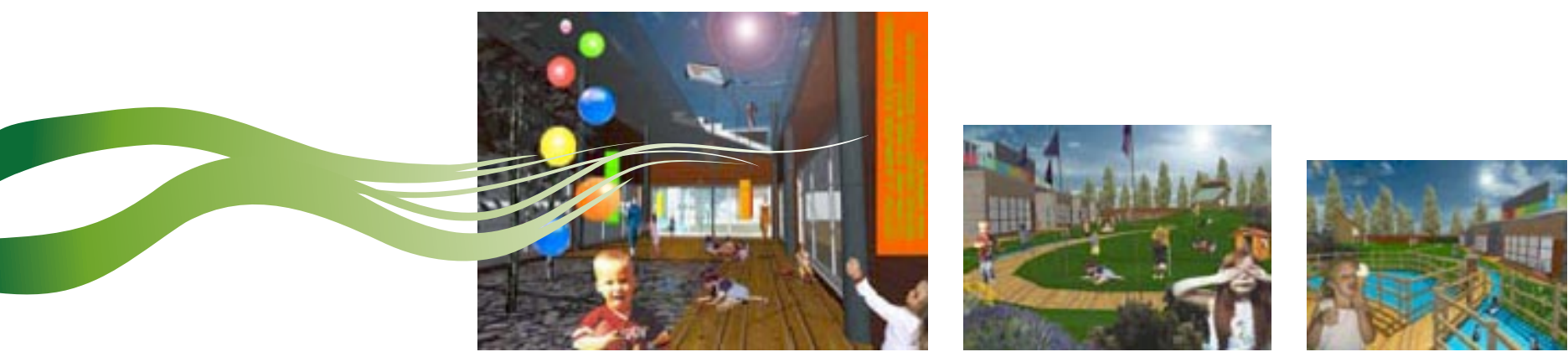


\section{Other areas}

In addition to the specialised areas intended for different age groups, there will be multi-purpose areas for adults and children. Spaces are planned for music, theatre and painting, as well as for meetings, performances and exhibitions. These spaces must be conceived in educational terms, from the colours of the walls, to the furnishings and their placement.

This project was awarded the 2006 Eurosolar First Prize (www.eurosolaritalia.org).

For more information, contact:

Giorgio Ponti

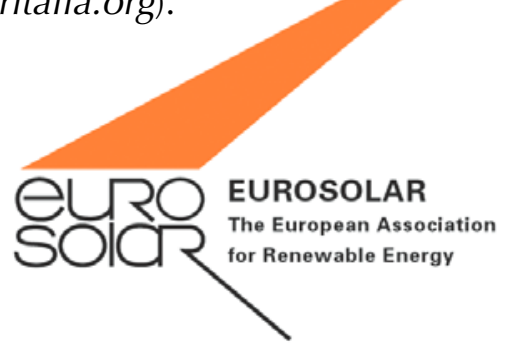

Area Co-ordinator for Educational Architecture

CISEM (Centre for Educational Innovation and Experimentation of Milan - Research Institute of the Province of Milan and Italian Provinces Union)

via Petrarca, 20

20123 Milan

Italy

E-mail: arch@giorgioponti.it

Website: www.giorgioponti.it

Project of the Department of Building Environment Science and Technology (BEST), Università Politecnico di Milano

Co-ordination: E. Zambelli, E. Pizzi and other teachers

Project operations: G. Ponti

Indoor play areas, landscape achitecture, and play and environmental learning facilities: M. Mandarini, F. Mandarini

Interior decoration: M. Grecchi, L. Malighetti, F. Gasparetto 


\section{ORGANISATION FOR ECONOMIC CO-OPERATION AND DEVELOPMENT}

The OECD is a unique forum where the governments of 30 democracies work together to address the economic, social and environmental challenges of globalisation. The OECD is also at the forefront of efforts to understand and to help governments respond to new developments and concerns, such as corporate governance, the information economy and the challenges of an ageing population. The Organisation provides a setting where governments can compare policy experiences, seek answers to common problems, identify good practice and work to co-ordinate domestic and international policies.

The OECD member countries are: Australia, Austria, Belgium, Canada, the Czech Republic, Denmark, Finland, France, Germany, Greece, Hungary, Iceland, Ireland, Italy, Japan, Korea, Luxembourg, Mexico, the Netherlands, New Zealand, Norway, Poland, Portugal, the Slovak Republic, Spain, Sweden, Switzerland, Turkey, the United Kingdom and the United States. The Commission of the European Communities takes part in the work of the OECD.

OECD Publishing disseminates widely the results of the Organisation's statistics gathering and research on economic, social and environmental issues, as well as the conventions, guidelines and standards agreed by its members.

This work is published on the responsibility of the Secretary-General of the OECD. The opinions expressed and arguments employed herein do not necessarily reflect the official views of the Organisation or of the governments of its member countries.

No reproduction, copy, transmission or translation of this publication may be made without written permission. Applications should be sent to OECD Publishing rights@oecd.org or by fax 331452499 30. Permission to photocopy a portion of this work should be addressed to the Centre français d'exploitation du droit de copie (CFC), 20, rue des Grands-Augustins, 75006 Paris, France, fax 331463467 19, contact@cfcopies.com or (for US only) to Copyright Clearance Center (CCC), 222 Rosewood Drive, Danvers, MA 01923, USA, fax 1978646 8600, info@copyright.com. 